\title{
APPENDIX TWO
}

A sample of theatre, music hall and cinema entertainment in Portsmouth, Coventry and Leeds, 1870-1939 


\section{APPENDIX 2}

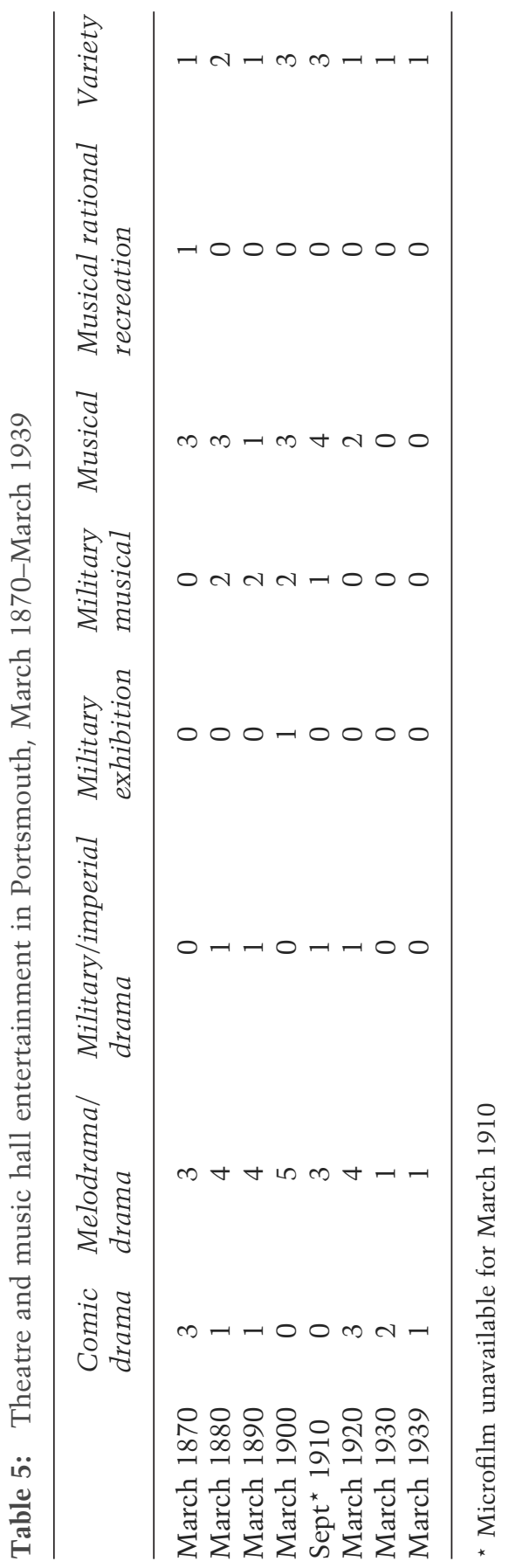

[ 213 ] 
APPENDIX 2

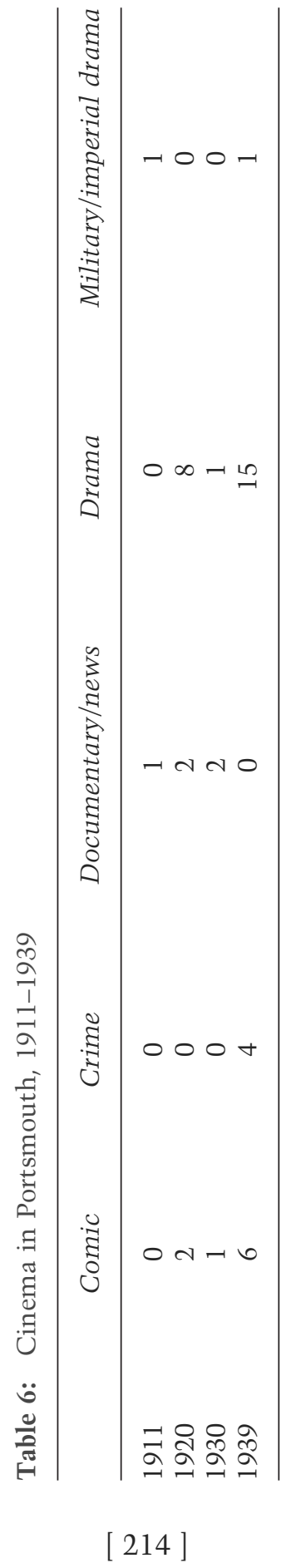




\section{APPENDIX 2}

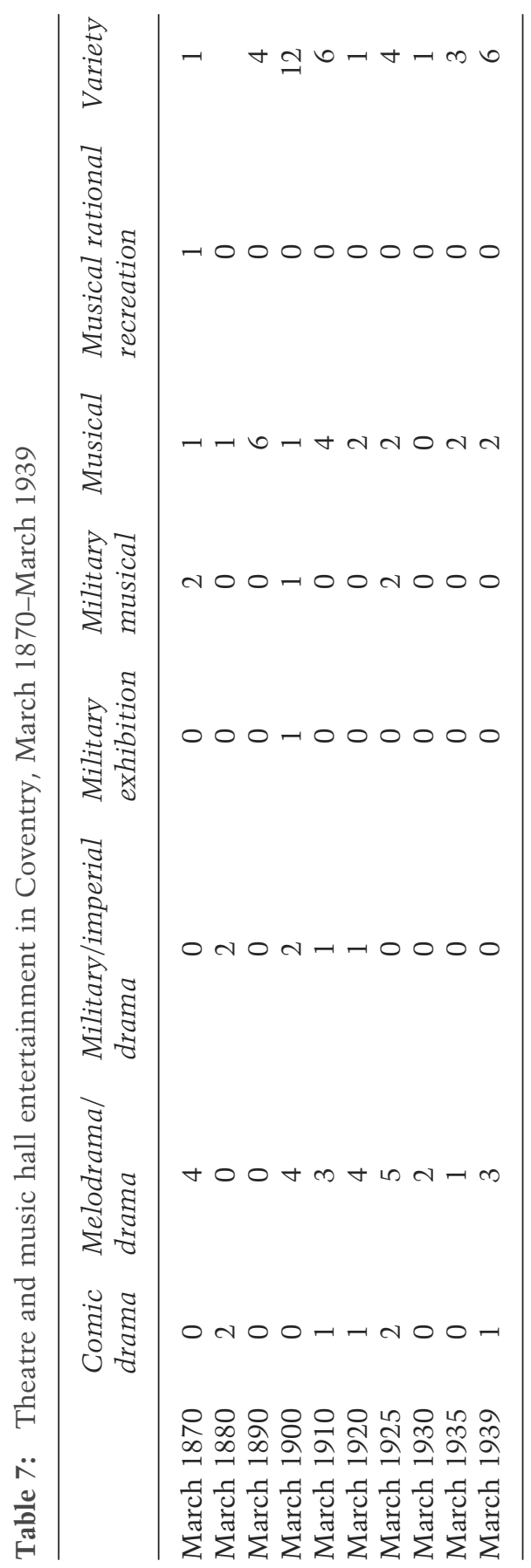

[ 215 ] 
APPENDIX 2

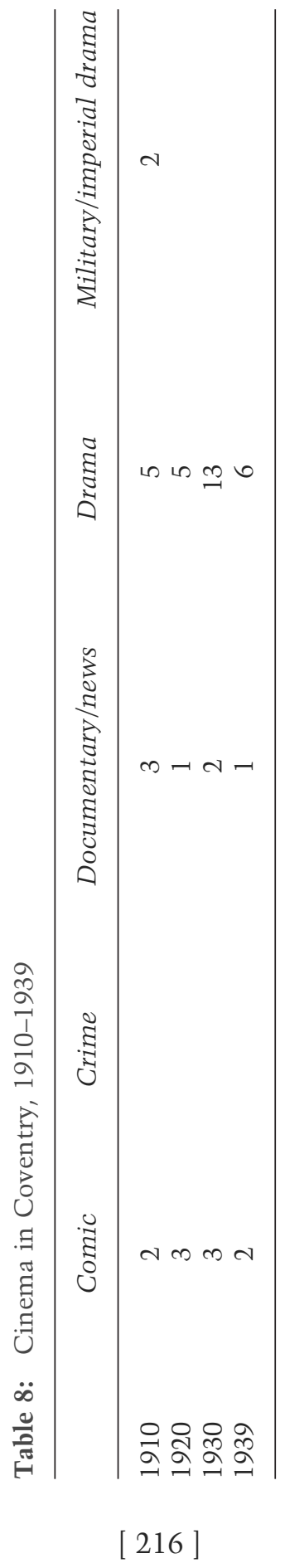


APPENDIX 2

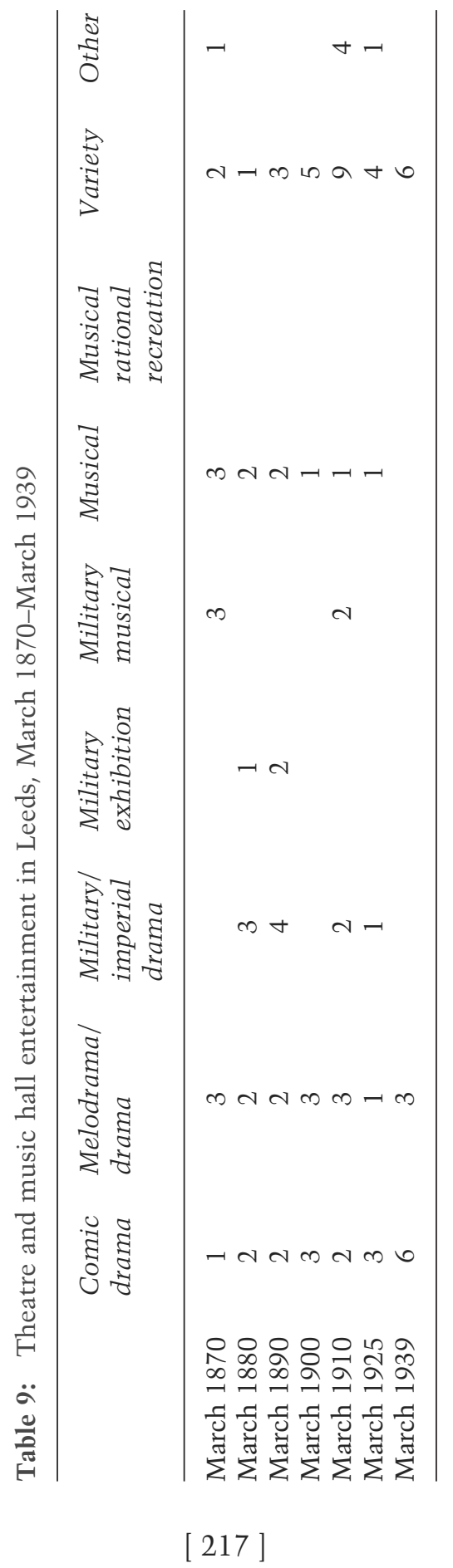


APPENDIX 2

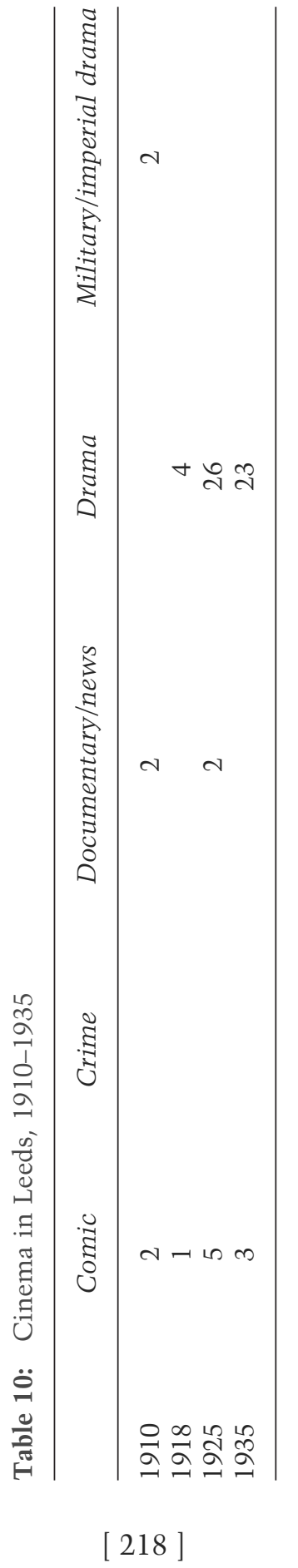

